\title{
Production Costs and Economic Competitiveness of the Pig Field in the Livestock and Meat Market, Cameroon
}

\author{
Ndebi Georges $^{1}$, Tchoumboue Joseph ${ }^{1}$, Mboko Arsène Valérie ${ }^{1,2}$ \\ ${ }^{1}$ Department of Animal Science, Faculty of Agronomy and Agricultural Sciences, University of Dschang, Dschang, Cameroon \\ ${ }^{2}$ Department of Animal Science, National Institute of Agricultural Sciences and Biotechnology of Masuku, Masuku, Gabon
}

\section{Email address:}

gndebi1960@gmail.com (N. Georges), jtchoumboue@yahoo.fr (T. Joseph), avmbokopoddy@yahoo.com (M. A. Valérie)

*Corresponding author

\section{To cite this article:}

Ndebi Georges, Tchoumboue Joseph, Mboko Arsène Valérie. Production Costs and Economic Competitiveness of the Pig Field in the Livestock and Meat Market, Cameroon. American Journal of Management Science and Engineering. Vol. 6, No. 1, 2020 , pp. 18-25. doi: 10.11648/j.ajmse.20210601.13

Received: November 19, 2020; Accepted: December 14, 2020; Published: March 10, 2021

\begin{abstract}
The capacity of the pig field to sustainably increase its wealth under a competitive situation was valued and compared on the Cameroonian livestock and meat market within a period of 6 months. The assessment items used as indicators to appreciate the economic competitiveness at national level were related to production costs on the market, field structuring, market size and quality of the product. The main results showed that the pig field is able to conquer more and to preserve its market share against substituting products competing by price. The main comparative advantage of the domestic pig field lies, basically, on its rationalization possibilities and production potential. Scattering of pig farms, mainly of small scale, all over the territory and using mostly family labor with a production system linked to the peasant lifestyle, limit the zoonoses spread and environment pressure and also contributes to the sustainability of pig field. Pig distribution channels are well structured enough to allow an easy flow of the products, with actors specialization at all levels, from livestock sale to roast meat. In addition, the development of the fifth quarter meat small scale roasting and processing industry in major metropolis is an indication of the capacity for innovation, constant productivity improvement and adaptation to environmental conditions. Moreover, the additional production costs in the pig market are relatively low, indicating a certain efficiency of the distribution system. However, the gaps between production and consumption prices, on the whole, are relatively important and reflect a situation of imperfect competition on the pig market. Also, the contractual advantages, without guaranteed prices or profit, the absence of any follow-up from the public authorities making it possible to modernize and restructure the pig field, create commercial infrastructures and external outlets, standardize transactions and ensure product quality to be presented on the market, are all factors with profound effects on the economic competitiveness of the Cameroonian pig field.
\end{abstract}

Keywords: Productivity, Rationalization, Commercial Network, Comparative Advantage, Quality, Pig

\section{Introduction}

The reinforcement capacities of local production units to meet constantly increasing demand in emerging countries is an effective way to improve the well-being and quality of life of populations, especially in rural areas. However, the countries of the franc zone have recorded, since the economic crisis coupled with the phenomenon of the devaluation of the CFA franc of the 1990's, strong fluctuations in the price of products and factors of production. These fluctuations, although varied by country depending on their dependence on the outside world for trade, have had impacts on economic activity in general and particularly in the agricultural sector [1]. The livestock subsector, particularly vulnerable to climatic or pathological hazards, has been largely unbalanced by the arrival on the local market of imported meat at subsidized prices. At the same time, the evolution of supply and demand for finished products has been altered as a result of reduced purchasing power and changes in the eating habits of mainly urban households. As immediate consequence, this development has led to significant changes in the relative competitive positions of the various animal production fields [7]. 
The Cameroonian state, for its part, has adopted certain economic policy strategies with the aim of stabilizing its macroeconomic balances and consolidating its economic growth. Protectionist measures towards imports of agropastoral products, such as tax and customs reforms and a common external tariff of $30 \%$ of the $\mathrm{CIF}^{1}$ value for finished products and for the revive the livestock subsector, have thus been taken. However, performance and cost-effectiveness allow to estimate the viability, access the adaptability and sustainability of a sector facing economic and environmental constraints. They depend on many factors among which production costs occupy a prominent place. In fact, the efficiency with which services are rendered and taxed on the market allows, nevertheless, to establish a certain link between relative competitive output and the performance of sectors in terms of economic results achieved [5]. According to the same source, pig is of a certain importance in the protein deficit reduction especially in rural areas and its contribution to agricultural Gross domestic Products is around $15 \%$. In addition, in the pig field where natural and structural advantages also play a greater role, it can be assumed that production costs remain decisive to explain the location of different productions.

The purpose of this study is therefore to assess the capacity of the pig field to increase its wealth and to maintain itself in a sustainable competitive situation, with competition being the source of excellence. In other words, it aims to identify and quantify the comparative advantages of the pig field in the livestock and meat market, to determine its strengths and weaknesses, its assets and threats and, finally, to propose ways and means to improve its productivity. However, the improvement of cost calculations and their use is of major interest for the management of fields and the assessment of their competitiveness in the market

\section{Materials and Methods}

Data for this study were collected during two successive surveys conducted over a period of 6 months on the development of agropastoral activities in the two main trade corridors likely to influence the domestic supply on the livestock and meat market. The Northern Corridor drained pigs produced from the northern regions (Adamaoua, North and Fare north) and neighboring countries to the Yaoundé market only, while the Western Highlands Corridor (west and northwest) supplied mainly the Yaoundé and Douala markets in pigs. To these productions, must be added that of urban and per-urban farms of these two consumption centers. The two surveys, of 3 months each, were carried out in the two corridors during the periods of intense activity on the market (December - February), marked by the end of year celebrations and funerals in the West and welding during the rainy season (July - September). A quota of 60 actors per corridor, including 20 farmers, 20 wholesalers or livestock dealers, 10 butchers or fresh meat traders and 10 roasters or

1 Cost, insurance, freight roast meat traders, was randomly selected on the basis of the volume of activities and the availability to answer questions. At the same time, 5 fish shops (Congelcam, Popular, Universal, Aqua-Mar and Queen-fish) were also surveyed to access the activities on the import channel of "frozen" meat.

The investigation procedure used was that of the field by product, which consists in defining the final outlet, then identifying the source(s) of upstream supply and finally, carrying out systemic and quantitative analyzes [5]. The quota sampling method was chosen to gather as much information as possible on the economic competitiveness indicators of a $\mathrm{n}$ animal production field. For the assessment of economic competitiveness, both domestic and international, there is a host of indicators or determinants, grouped together in price competitiveness and non-price competitiveness [3, 6-8]. The indicators used for price competitiveness or market performance were related to final selling price (FSP) of the product on the market, production costs (prices at the different links in the pig distribution chain), transaction costs (relating to the transfer of the product), profit margins generated at each link of the chain and profitability ratio or capital turnover. Regarding nonprice competitiveness indicators, the criteria retained on the basis of comparative advantages were related to field structuring and characteristics of the pig market (capacity of markets, actors, products and operations) and (size or capacity of the market, degree of product differentiation and qualify, marketing and competition structures and, pricing mechanisms). It is important to note that the assessment of the economic competitiveness of the pig field has been limited at the national level, given the lack of necessary information.

In the absence of reliable official statistical databases, the data collected from surveys and direct interviews conducted with the various stakeholders established in the various pig commercial channels have been used to draw up a quantified assessment of their achievements. Additional information on the volume of transactions, the various health taxes and levies carried out, slaughter costs, etc. were obtained from the ledgers of the Animal Production Development Society (SODEPA), the Veterinary and Zootechnical National Centers (VZNC), the Cameroon Railway CAMRAIL and customs services. Pig production costs were recorded at their fair value declared by the farmers due to lack of the means of verification. In the calculation of transaction costs, direct costs (which depend on the volume of goods) such as collection and packaging costs, approach costs, slaughter, storage and maintenance costs, selling costs and other costs as well as taxes and miscellaneous losses were taken into account. Estimating the total cost of producing one kilogram carcass on the livestock and meat market thus allowed an assessment of the efficiency with which the services are render taxed. The financial profit or trader's profit margin, which is the difference between e income received and the cost paid in the production activity, was also used as a comparative basis. It is a reliable indicator of the operational profitability of an activity in the sense of orientation of the 
resources for more efficiency that allows to gauge the profit margin realized by the purchasing activity of the merchant. It has been access at each level of the distribution chain in terms of the mark-up or brand rate, the formula of which is defined as follows:

$$
M B=\frac{\text { Final selling price }- \text { Buying price }}{\text { Final selling price }} \times 100
$$

In addition, the profitability ratio of the activity (commercial margin to the turnover) and the speed of the capital turnover (equivalent to the purchase, route and sale of the product times, to which the merchant's rest should be added) were used to estimate the increase in the field wealth. The assessment of the quality of the product or the ability to give maximum satisfaction to the consumer was limited to: appearance, conformation, color of the dress and thickness of the bacon. At the same time, the same data were collected on substitute products that means imported or "frozen" meat to measure the comparative effects. Other comparative advantages, such as the capacity for innovation and constant improvement of productivity, were also determined from the functionalities of the field. However, macroeconomic factors such as externalities, production systems, etc., necessary for the assessment of the competitiveness of a field, were not included, given the lack of reliable information.

The data thus collected using a survey sheet and supplemented by direct interviews were used to determine the parameters of the study. The presentation, analysis and discussion of the results are contained in the following developments

\section{Results: Presentation and Analysis}

\subsection{Price Competitiveness Assessment}

\subsubsection{Distribution and Composition of Pig Price According to the Local Supply Channels}

The price of pig includes the cost of producing or acquiring the product to which are added intermediary services consisting of transaction costs and profit margin. Table 1 presents the level and distribution of the price at each stage of the distribution chain.

Table 1. Distribution and composition of pig price according to the local supply channels (FCFA/kg carcass weight).

\begin{tabular}{|c|c|c|c|c|c|c|}
\hline \multirow{3}{*}{$\begin{array}{l}\text { Distribution and composition of } \\
\text { pig price }\end{array}$} & \multicolumn{6}{|c|}{ Local supply channels } \\
\hline & \multicolumn{2}{|c|}{ Northern } & \multicolumn{2}{|l|}{ Western } & \multicolumn{2}{|l|}{ Average } \\
\hline & Amount & $\%$ FSP & Amount & \%FSP & Amount & $\%$ FSP \\
\hline Producer & 1179.49 & 40.18 & 1777.16 & 63.14 & 1478,33 & 50,91 \\
\hline Production costs & 652.86 & 22.24 & 1075,58 & 38.22 & 869.12 & 29,93 \\
\hline Profit margin & 526.63 & 17.94 & 701,58 & 24.92 & 609.21 & 20,98 \\
\hline Brand rate & 17.94 & & 24.93 & & 20.98 & \\
\hline Livestock dealer & 557.77 & 19.00 & 157,84 & 5.61 & 354.65 & 12.21 \\
\hline Profit margin & 346.67 & 11.81 & 100.49 & 3.57 & 220,12 & 7.58 \\
\hline Brand rate & 19.00 & & 3.57 & & 7.58 & \\
\hline Butcher & 555.66 & 18.93 & 430.05 & 15.28 & 496.37 & 17.09 \\
\hline Transaction costs & 210,39 & 7.17 & 128.83 & 1.02 & 173.12 & 5.96 \\
\hline Profit margin & 345,27 & 11.76 & 301.22 & 14.26 & 323.25 & 11.13 \\
\hline Brand rate & 11.76 & & 10.70 & & 11.13 & \\
\hline Meat roaster & 642.77 & 21.90 & 449.14 & 15.96 & 545.65 & 18.79 \\
\hline Profit margin & 550.22 & 18.74 & 400.68 & 14.24 & 472.15 & 16.26 \\
\hline Brand rate & 18.74 & & 14.24 & & 16.26 & \\
\hline \multicolumn{7}{|l|}{ Synthesis (field income) } \\
\hline Final sale price (FSP) & 2935.69 & 100.00 & 2814.73 & 100.00 & 2903,76 & 100.00 \\
\hline Total production cost (TPC) & 1166.68 & 39.74 & 1210.31 & 43.00 & 1201.27 & \\
\hline Profit margin (PM) & 1769.01 & 60,26 & 1604.42 & 57.00 & 1673.73 & 41.78 \\
\hline Brand rate $(\mathrm{MB})$ & 60.26 & - & 57.00 & - & 57.64 & 58.22 \\
\hline
\end{tabular}

From the results of this table, it can be seen that the production costs of pig on the livestock and meat market are, on the whole, relatively low and decrease as production activity moves downstream. In contrast, the marketing margins, generated at each segment of the chain, increase dramatically as the production activity moves in the same direction, that is, towards the consumer and end user. By taking into account the channel, the marketing margins were relatively higher in the northern channel, compared to that of the west, where the costs of producing pig on the market were rather higher. Regardless of the channel, these costs represent around $30,5,6$ and $3 \%$ of the price to the producer, the livestock dealer, the butcher and the meat roaster, respectively. Profit margins, on the other and, were relatively higher among meat roasters $(16 \%)$ and butchers $(11 \%)$, compared to livestock dealers $(8 \%)$, who, despite their role in regulating supplies, presented raw and low value products on the market. This could be explained in part by the degree of the product processing which remains the prerogative of the latter. However, analysis of the relationship between profit margins and transaction costs revealed the existence of imperfect competition in the pig market, indicating that the gap between production and consumption prices was due to the increased profit margins for traders. In fact, depending on 
the purchase price, the financial availability of customers, the market activity and $\mathrm{luck}^{2}$, the profit margin of the livestock trader ranged from 8,000 to 13,000 FCFA and that of the meat trader from 11,000 to 18,000 FCFA per pig sold. The analysis of the brand rate of the activity showed that the pig production on the livestock and meat market, all other things being equal, is a promising field of activity, whatever the product presented or the corridor used. Despite the high share of the final sale price which goes to the producer (51\%), his brand rate $(21 \%)$ remains considerably lower than that of all meat dealers $(35 \%)$. This rate was relatively higher by the northern corridor $(60 \%)$, compared to that of the west $(57 \%)$, where the final sale price was lowest. The differences observed in the two trade corridors were said to be due to the economies of scale in the transfer of livestock from production zones to consumption markets. In fact, the production of pigs from the northern regions was channeled to the Yaoundé market by rails in large quantities reducing thus the cost of transport per pig, while that of the western highlands was channeled by roads in small quantities.

\subsubsection{Distribution and Composition of Pig Price According to the Import Supply Channel}

Price competitiveness also refers to substitute products that compete on price. Table 2 presents the level and composition of the price of imported or frozen pig meat.

Table 2. Distribution and composition of pig price according to the import supply channels (FCFA/kg carcass weight).

\begin{tabular}{lll}
\hline \multirow{2}{*}{ Distribution and composition of pig price } & \multicolumn{2}{l}{ Import supply channel } \\
\cline { 2 - 3 } & Amount & $\%$ \\
\hline Importer gross margin & 894.80 & 54.71 \\
Import cost & 849.3 & 49.29 \\
Profit margin & 45.50 & 5.42 \\
Brand rate & 2.78 & \\
Trader (fishmonger) gross margin & 740.70 & 45.29 \\
Transaction cost & 68,20 & 9.21 \\
Profit margin & 672,50 & 36.08 \\
Brand rate (MB) & 41.12 & \\
Synthesis (field income) & & \\
Final sale price (FSP) & 1635.50 & 100.00 \\
Total production cost (TPC) & 917.50 & 56.01 \\
Profit margin (PM) & 718.00 & 43.99 \\
Brand rate (MB) & 43.90 & - \\
\hline
\end{tabular}

Source: Department of statistics and national accounts [DSNA, 2013]

From the analysis of the above results, it emerges that the importation of frozen meat remains an income-generating activity for all traders located in this corridor. Comparison between the different links in the product value chain indicated that the brand rate recorded were, on the whole, relatively higher (44\%). It was highest for traders $(41 \%)$, compared to the importer (3\%) whose import costs represented (49\%) of their gross margin. The analysis of the profitability ratio of the pig production revealed the superiority of the local channel, compared to that of imports, indicating an advantageous situation of the local pig field.

2 Best business
But, this difference in profitability may be at the level of risk. On one and, the import of frozen meat mainly used the dead channel, the risks of which are linked only to freezing with minimal losses. On the other hand, local meat distribution channels used, at the same time, both live and dead channel s with all possible risks of losses due to transport, disease, storage, etc. Indeed, imports of cut meat consisted mainly of pig legs, tails and chops, which perish with difficulty. However, it is obvious that the higher the risks, the more profitable the activity and vice versa. The speed of capital turnover, according to the statements of the various actors installed in these corridors, was a function of the supply channel and the nature of product. The difference between the trade corridors was mainly due to the travel time (six days minimum for the north corridor and six hours on average for the western one). As for the duration of the sale, it varied according to the periods as illustrated in figure 1 . However, a livestock dealer could sell, an average of 200 pigs per month. But, the difficulty for the producer, to obtain information on the actual price and quantities of products on the market, made transactions uncertain, thus, benefiting the traders who had control over them. Regarding the purchase time, most dealers reported that they are generally assisted by local brokers or traders and even conveyors whose main roles were to guarantee the farms production and to transport the products to the market concerned. However, for unassisted traders, the same workforce could be obtained in three periodic markets. Ultimately, the monthly average speed of capital turnover, plus the trader's rest, could be estimated at 30 and 36 days for the western and north channels respectively. However, the volume of activities did not allow these traders to cope with the risks surrounding this activity in terms of various losses due to the disease and transport of live animals. In addition, most of them first worked for large traders before they could set up on their own.

\subsection{Assessment of Non-price Competitiveness}

\subsubsection{Pig Field Structuring and Characteristics of the Pig Markets}

Figure 1 presents the organizational and functional approaches of pig distribution with the different forms of marketing used by the various actors of the field.

From the analysis of the field structuring, it can be noted a form of strategic segmentation of the pig market with actors grouped around a specialization by product, allowing an easy flow of the product. Surveys carried out in the pig trade corridors revealed that the distribution of pig on the Cameroonian livestock and meat market is done through an impressive number of channels. The length and importance of these channels depends on the number of intermediations that the product undergoes before reaching the consumer and end user and the volume of products processed. However, their number varied depending on the distribution channel and the nature of the product. Overall, the structuring of the pig field clearly indicated a form of vertical integration between the various components of the field, ranging from the production of live animals to its consumption, including 
the processing of pig into ready-to-eat products, indicating the capacity for innovation and constant improvement of productivity. In addition, the sale of livestock on the farm or on the market road had a benefit, at the producer level, which is the reduction of marketing costs relating to transportation, storage and handling, taxes, losses and various hassles.

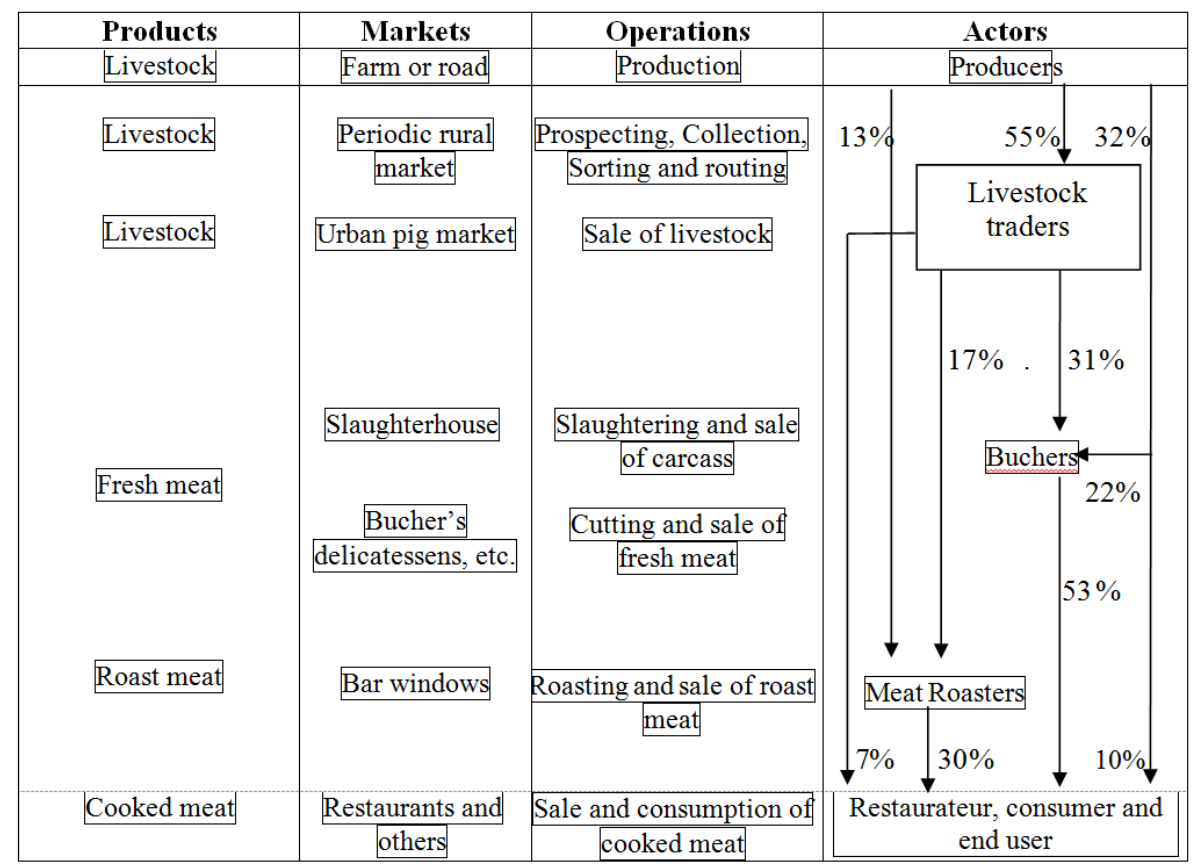

Figure 1. Pig field structuring.

\subsubsection{Market Size or Market Capacity}

The analysis of the level of activity recorded in the livestock market, in terms of profitability and the number of traders (figure 2), revealed that pig production in the livestock and meat market appears to be linked to the way of life of populations.

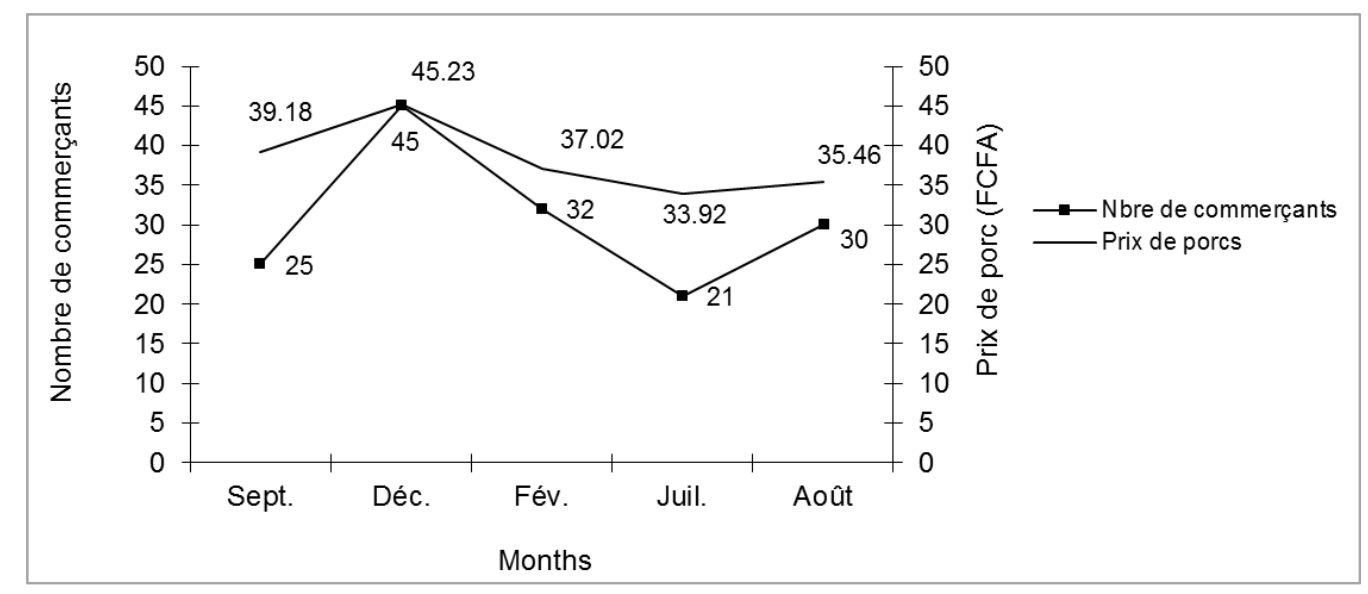

Figure 2. Evolution of the number of traders according to the pig price on the market.

The volume of activities also varied according to the evolution of agropastoral activities as described in figure above. According to the results of the surveys carried on the meat market, the average volume of sales per day varied depending on the periods, from 28 to $29 \mathrm{~kg}$ for butchers and 37 and $32 \mathrm{~kg}$ for roasters based in Yaoundé and Douala respectively. The demand for pig in the meat market derives from consumer demand which derives from their range of preferences and according to their incomes. Likewise, the supply of pig in the livestock market derives from the supply of the producer which is a function of price factors and nonprice factors such as psychological state, etc. All of these factors seem to stem from the impact of agropastoral activity schedule as illustrated by the figure above. Seasonal and cyclical trends in the pig production were marked by a peak in December, the season of late-year celebrations and funeral in the West regions which run between November and March. There were then a gradual decrease in the level of pastoral activities during the cultivation period (April and July), followed finally by a resurgence of activities on the 
market in August due to the Assumption festival marked by baptisms and association congresses in some villages.

\subsubsection{Degree of Product Differentiation and Quality}

From the observations made, product differentiation in the pig market was made on the basis of source of supply: fat western pig was more appreciated with roasters while lean northern pig was preferred by butchers and individuals. However, the products presented on the livestock and meat market were of variable quantity and quality and varied according to the corridor and type of product. In the livestock market, the animals featured were of different conformation and phenotype, allowing customers to make choices based on their portfolio and scale of preferences. Relative price differences in the livestock market were also observed between pigs from the north, whose bacon thickness was recognized to be very low and preferred by butchers, compared to those from the western highlands where this bacon thickness was more pronounced but most preferred by roasters. In the contrast, the distribution of the butcher's stalls visited revealed that pig meat presented was $29 \%$ uncleaned and non-defatted, $46 \%$ clean and non-defatted and only $25 \%$ of them presented cleaned and defatted pig meat. No distinction was made between meat with and without bones. However, the comparison of the market values of these different meats in stalls showed a direct relationship between the price and the degree of the product treatment. It has been established that animals slaughtered outside official slaughter point, although of doubtful quality (no control by veterinary services), were sold at the same price as controlled meat)

\subsubsection{Marketing Structures}

From the observations made on the livestock markets, there was four large pig sale outlets in the Yaoundé market (quay, Bankolo, Central market and Etoudi) and only one in Douala (central market) for a total of 45 officially established livestock traders, including 34 and 11 respectively in Yaoundé and Douala. However, their number also varied depending on the peak periods in the market. The marketing infrastructures available in pig markets were basic equipment that cannot ensure a better match to market conditions able to meet consumer demand. The material facilities on the livestock markets visited were limited to basic constructions in local materials covered with sheets and divided into lodges of varying capacities with uncemented floor. As for the meat markets, the surveys counted 24 and 26 tiled butcher's stalls in Yaoundé and Douala respectively and several others built in wood or scattered on the ground and in all road corners. Overall, the current physical organization of pig markets did not allow animals to be stored and maintained for more than a week, nor did it guarantee the hygienic conditions necessary for trade. The absence of infrastructure is very detrimental to the regulation of market activities because and standardization of transactions.

\subsubsection{Competition Structures}

The economic functions of pig production and supply on the livestock market, where demand was largely expressed by the livestock traders (55\%), were devolved to livestock producers. In their turn, livestock traders, assisted by brokers, conveyors and transporters, carried out all the collection, assembly and transfer operations of the product on the urban consumer market, where demand was expressed; for the most part, by meat dealers (48\% of which 31 and $17 \%$ respectively for butchers and roasters), whose main functions consisted in the permanent adjustment of their supplies to the needs and tastes of the customers. In fact, the economic functions devolved to the meat dealers concerned the slaughter, cutting and retailing of fresh or processed meat to be consumed by households and others. The sale of fresh meat mainly concerned butchers who did the majority $(53 \%)$ of household supplies. The sale of roast meat was a nascent activity, but of very large scope in urban areas. It concerned roasters who, in addition to the functions devolved to butchers, practiced cooking and / or roasting pieces of meat. These intermediaries obtained their supplies mainly from resellers or butchers $(57 \%)$. Their main customers consisted of drinkers and others. In addition to these main actors, the livestock and pig market was also driven by other intermediaries such as transporters, brokers, scrapers, etc. which were paid per head of pig or rewarded with part of the 5th quarter. Alongside this classic distribution scheme for pig products, there were other actors specialized in the sale of the 5th quarter or fresh or processed casings, thus playing the role of recovery.

\subsubsection{Price Formation Mechanisms and Marketing Conditions}

Surveys carried out on the livestock and meat market showed that the price policies practiced on the pig markets were different and varied according to the type of product. In the livestock market, the price policy used was that of competitive equilibrium, based on the conformation of the animal that is, done at the estimate where-quantity is rigid and price being the adjustment variable that allows exchange. According to the elasticity of supply and demand on the market, the sale of the animal was subjected to a long negotiation between the seller and the buyer to finally lead to the exchange prix. The bargaining force or ability of an actor to obtain advantageous conditions during a commercial transaction was strongly linked to the access to information on prices and quantities, the psychological state of the seller, the very perishable nature of the product, etc. In contrast, the price policy practiced in the meat market was that of rationing equilibrium where price is rigid and quantities being the adjustment variable that allows exchange. It must be recognized that meat dealers had a definite influence given their strategic position allowed the market conditions, and the fraud on price and quantities exchanged, carried out from the rigged masses, were regular and represented about $20 \%$ of the quantities really exchanged

Ultimately, the assessment of non-price competitiveness showed that the pig marketing characteristics seem relatively efficient to guarantee the factors of competitiveness. The upstream and downstream trader networks of the field guarantee maximum flexibility on the quantities sold and prices charged, while the links within these networks allowed 
to reduce the risks associated with the transport and storage of products. However, the lack of adequate marketing strategies in terms of the degree of packaging of the product was a serious impediment to the emergence of this field.

\subsection{Discussion}

A product has a comparative advantage when its production on the market can be done at a very low cost due to the variability of the meanly local resources and production strategies $[13,14]$. The results of the investigations carried out in the main pig trade corridors to determine the capacity of the pig field to sustainably increase its wealth under a competitive situation, have allowed to assess the efficiency with which services are rendered and taxed in the pig market. The same work carried out elsewhere [8] has shown, in particularly, that the organization of distribution channels as well as the quality of products are important parameters in assessing the compared or comparative advantages of certain fields. In fact, trading networks, particularly structured around hierarchical ties and intra-family or intra-ethnic solidarity, allowed a form of specialization of actors at all levels of the pig production chain in order to facilitate the flow of the product on the market [12]. The upstream and downstream links of the field were such as to guarantee maximum flexibility on the quantities sold and the prices charged, while those within the networks allowed to reduce the risks associated with the breakdown of stocks, the transfer of products, etc. However, the structuring role of distribution channels remained dynamic but, there were a lack of rules of discipline and morality allowing their reorganization. The individual behavior of actors did not allow standardization of the supply and transactions on the pig market. The concept of pig quality, according to the ISO 8402 standard which relates to all the organoleptic, biochemical, physicochemical, biological and technical properties giving it the ability to meet expressed or implied needs, remained very little respected here as in animal production fields observed elsewhere [15]. The concern for promoting the quality of local products, which essentially depends on the organization of the field and the skills of all stakeholders and their rational consumption, should be essential to insure the adequacy of the supply and demand and to reduce the risk of surplus substitute products. With a view to lifting the restrictions on meat imports, it was imperative that the national economy be able to offer consumers products of equal quality at a competitive price. In addition to these comparative advantages, the pig thus ranks among domestic animals meeting the necessary conditions for advantageous speculation and which could rapidly reduce the growing protein deficit. In addition, the red revolution observed in the northern part of the country led to a growth of its pig herd of around $290.4 \%$ and thus, placing pig in the lead $(60 \%)$ in meat consumption in Cameroon [5]. The pig production parameters, although linked to peasant lifestyle, remained fairly good, with an average of 2 farrowing per year with litters of 5-6 weaned piglets per sow (4). The dispersion of pig farms throughout the national territory, was also a brake on the spread of zoonoses and pressure on the environment. All these factors contribute to guarantee the sustainability of the Cameroonian swine sector [14]. On the other hand, the development of an artisanal meat roasting industry. All these factors should contribute to ensure the sustainability of the Cameroonian pig field [14]. On the other hand, the development of a small scale pig roasting and processing industry of the fifth quarter in large urban areas was also a major indicator of non-price competitiveness which determines the capacity for innovation and continuous improvement of productivity and adaptation of the pig field to environmental conditions. MINEPIA [9] estimated at 250 the number of pig rosters in the alone city of Yaoundé. The distribution and composition of the pig price showed that the pig field sector generates stable and remunerative jobs in view of the recorded profitability brand as reported elsewhere [5]. the meat dealer's profit margin was higher. Compared to that of that of the producer-importer, indicating that the more the product is processed the greater the profit $[2,5]$.

It must be recognized, however, that this study was limited to the national level, due to a lack of available information, although the economic competitiveness of a field is defined in relation to its position on the markets (domestic and external) vis-à-vis of its main competitors. However, it is a good illustrate of the functioning of most of the agricultural production fields, especially animal production, without any support from the public authorities. Modernization and restructuring of the whole system is necessary for better productivity and profitability of labor [2]. In addition, the obstacles to the competitiveness of the productive sector and local agropastoral farms concern, in particular, the lack of adequate infrastructure for pig processing and external outlets, financing and credit, insufficient investment and support services to the private field [10].

\subsection{Conclusion and Perspectives}

The aim of the study was to assess the economic competitiveness of the pig field on the Cameroonian livestock and meat market in order to identify its strengths and weaknesses, as well as assets and threats and to suggest ways and means of improving its capacity to $i$ to maintain itself in a sustainable competitive situation. Our results showed that the pig production in the livestock and meat market remains an income generating activity for all actors located in the main trade corridors. The current and potential competitiveness of this field is based on the possibility of rationalization that it presents, its capacity to reduce the protein deficit at a lower cost and on a growing hand-made processing industry. this can be sustainably ensured by the existence of a multitude of small scale farms, mostly family owned scattered throughout the national territory, placing on the market a wide range of products ranging from live animals to roast meat, in variable quantity and quality. However, the current conditions of the livestock and meat market make it difficult to provide the stable bases necessary for the construction of sustainable development strategies for 
the pig field. Thus, improving the competitiveness of this field requires interventions on one or all of the factors studied above in order to increase its productivity and create the conditions for a sustainable and balanced competitive operations on the pig market. The disparities observed in the main trade corridors are useful to facilitate the restructuring of the field and increasing its efficiency. The establishment of more efficient marketing facilities for products and the modernization of production infrastructure can make a significant contribution to improving competitiveness of the pig field. Furthermore, the contractual advantages, without guaranteed prices or profit and the absence of monitoring by public authorities and external outlets to ensure product quality, have profound effects on economic competitiveness and viability of the pig field Finally, the actors for their part, must increasingly find ways to add value to their products in order to increase their income and maintain the competitiveness of the pig field in the livestock and meat market. Although, the explanation of the concept of economic competitiveness seems erroneous at the national level, the search for a conceptual framework, capable of integrating all of its dimensions, constitutes a part of deepening necessary to advance research in this field.

\section{Acknowledgements}

This pedagogical resource has been prepared and written to help strengthen the research capacity of Animal Productions field. Its authors express their gratitude to the Department of Animal Productions, Faculty of Agronomy and Agricultural Sciences of the University of Dschang for its moral and material contribution to the achievement of this work. They also thank Professor Joseph Tchoumboué for his encouragement to the research work.

\section{References}

[1] Barrier C., Bellot JM, Sarniguet J., Thomas P. and Chartier P., (1996). The revival of the livestock sector in the franc zone countries after the devaluation. Ministry of CooperationFrench Development fund. $107 \mathrm{p}$.

[2] Bennet J. G., (2003). Diagnostic study of the competitiveness of the Cameroonian economy. Phase I. CRETES. 308 P.

[3] Champion F and Chotteau P. (2013). Competitiveness of the Brazilian beef and veal sector and place on the world market. Renc. Search. Ruminants. Vol. 20. Pp 37-360.
[4] Defang HF, Kana J-R, Bime M-J., Ndebi G., Yemele F., Zoli P. A., Manjeli Y., Teguia A. and Tchoumboue J., (2014). Socioeconomic and technical characteristics of pig farming in the urban and peri-urban zone of Dschang-West region of Cameroon. Discourse Journal of Agriculture and Food Sciences. Vol. 2 (1): Pp 11-20.

[5] Georges Ndebi, F. Kamajou and B. Dia Kamgnia, (2011). Trade margins and development of livestock/meat mgooarket. Ed. books. Europe. 115p.

[6] Lachaal L., (2001). Competitiveness: Concepts, definitions, and applications. In Laajimi A. (ed) The future of agro-food exchanges in the Mediterranean basin: the challenges of globalization and the challenges of competitiveness. Mediterranean Options Books. n. 57. Pp 29-36. $\mathrm{http} /$ om. ciheam.org/article.php?IDPDF $=1600240$

[7] Latruffe, L. (2010). Competitiveness, productivity and efficiency in the agriculture and agri-food sectors. Ed. OECD. http://dx.doi.org/10.1787/5km91nj6929p-fr.

[8] Mian Oudanang Koussou, Guillaume Duteutre, (2012). Competitive factors for the swine industry in the Logone basin. Laboratory for veterinary and zootechnical research in Farcha-Chad. $13 \mathrm{p}$.

[9] MINEPIA, (2011). Annual Report.

[10] Ndebi G., Niba A. T and Defang H. F. (2014). Economic rationality and management objectives for the production of guinea pigs (Cavia porcellus L.) in tropical areas. Tropicultura. 33 (1). Pp 26-37.

[11] Ndebi G., \& J Ongla. (2016). Functioning of pig distribution systems in Cameroon. Tropicultura $(24,2)$. Pp 73-81.

[12] Ndébi G.; Kamajou F. et Ongla J., (2009). Analysis of the pig production development constraints in Cameroon. Tropicultura. 27 (2). Pp 70-76.

[13] OECD, (2008). Breeding and regional market in the Sahel and West Africa: Potential and Challenges. 182 p. http//wwww.oecd.org/dataoecd/37/51/40279092.pdf

[14] Preston T. R. and Murgeitio E. (1992). Strategy for sustainable livestock production in the Tropics. CIPAV-SAREC, Cali Colombia, 89 p.

[15] Salifou C. F. A., Youssao A. K. I., Ahounou G. S. Tougan P. U., Farougou S., Mensah G. A., Clinquart A., (2013). Assessment criteria and factors affecting the characteristics of the carcass and the quality of beef. Annals of Vet. Med. 157. Pp 27-42. 